\title{
AVALIAÇÕES DE LARGA ESCALA EM MUNICÍPIOS BRASILEIROS NO CATÁLOGO DE TESES E DISSERTAÇÕES DA CAPES
}

\author{
Ana Lidia Lopes do Carmo Monte \\ Eloisa Maia Vidal
}

\section{Resumo}

$\mathrm{O}$ artigo analisa as produções acadêmicas sobre políticas de avaliação em municípios brasileiros, a partir do Catálogo de Teses e Dissertações da Capes, no período 2005 - 2017. É uma pesquisa bibliográfica e tem o intuito de elucidar o tema nos estudos acadêmicos, com uso de verbetes considerados relevantes e abrangentes. Foram identificados treze trabalhos relacionados com avaliação educacional em municípios brasileiros, sendo 3 teses e 10 dissertações, que envolvem 9 estados e 32 municípios. Os resultados apontam pistas interessantes, como o envolvimento dos atores escolares na implementação das estratégias concebidas pelos órgãos municipais, estadual e federal visando à melhoria dos indicadores educacionais atrelados às políticas de avaliação e que a centralidade que as avaliações de larga escala ocupam no cotidiano dos gestores faz com que eles tenham pouca margem de manobra no processo de implementação das políticas.

Palavras-chave: produção acadêmica; políticas de avaliação educacional; municípios brasileiros.

\section{LARGE SCALE ASSESSMENTS IN BRAZILIAN MUNICIPALITIES IN THESES AND DISSERTATIONS CAPES CATALOG}

\begin{abstract}
This paper analyzes the academic productions about evaluation policies in Brazilian municipalities, from the survey of national theses and dissertations, from 2005 to 2017 Theses and Dissertations Capes Catalog. It is a bibliographic research and aims to elucidate the theme in academic studing using entries we considered relevant and broad. It was possible to identify 13 studies related to educational evaluation in Brazilian municipalities, from which were found 3 theses and 10 dissertations, involving 9 counties and 32 municipalities. The results point to interesting clues, such as the involvement of school actors in the implementation of strategies designed by municipal, state and federal agencies aimed at improving educational indicators linked to evaluation policies and that the centrality that large-scale evaluations occupy in the daily lives of managers it leaves them little margin for maneuver in the policy implementation process. Keywords: academic production; educational evaluation policies; brazilian municipalities
\end{abstract}

\section{EVALUACIONES A GRAN ESCALA EM MUNICÍPIOS BRASILEÑOS EN EL CATÁLOGO DE TESIS Y DISERTACIONES DE CAPES}

\section{Resumen}

El artículo analiza producciones académicas sobre políticas de evaluación en municipios brasileños, basado en el Catálogo de Tesis y Disertaciones de Capes, en el período 2005 - 2017. Es una investigación bibliográfica y tiene como objetivo dilucidar el tema en estudios académicos, utilizando entradas consideradas relevantes y completas. Se identificaron 13 estudios relacionados con la evaluación educativa en municipios brasileños, incluidas 3 tesis y 10 disertaciones, que involucraron a 9 estados y 32 municipios. Los resultados apuntan a pistas interesantes, como la participación de actores escolares en la implementación de estrategias diseñadas por agencias municipales, estatales y federales que apuntan a mejorar los indicadores educativos vinculados a las políticas de evaluación y que la centralidad que ocupan las evaluaciones a gran 
escala en la vida cotidiana de los gerentes les deja poco margen de maniobra en el proceso de implementación de políticas.

Palabras clave: producción académica; políticas de evaluación educativa; municipios brasileños.

\section{INTRODUÇÃO}

Este artigo analisa as produções acadêmicas sobre políticas de avaliação educacional em municípios brasileiros, a partir do levantamento das teses e dissertações nacionais, publicadas de 2005 a 2017, no Catálogo de Teses e Dissertações da CAPES. Este período é marcado pela relevância que as avaliações externas de larga escala ganham, com a criação do Índice de Desenvolvimento da Educação Básica (Ideb) e o protagonismo que elas assumem para a política educacional.

O levantamento se propõe a elucidar aspectos relacionados às políticas de avaliação de larga escala em municípios, dentre os quais se destaca: quem, quando e onde foram produzidas essas investigações; objetivos que buscaram alcançar; demarcação territorial; instrumentos de coleta dos dados utilizados; critérios empregados para escolha das escolas participantes; sujeitos estudados; resultados apontados e referenciais teóricos adotados. Caracteriza-se como uma pesquisa bibliográfica, baseada em um rigoroso inventário, com o intuito de elucidar como se encontra o tema no estado atual da ciência e no que está ao alcance do pesquisador (NÓBREGATHERRIEN; THERRIEN, 2010).

O interesse por este tipo de estudo se deu em decorrência da revisão de literatura necessária para uma pesquisa em andamento, que objetiva investigar como as políticas de avaliação de larga escala têm refletido no desempenho crescente no Ideb de 2005 a 2017 no ensino fundamental em dois municípios do estado do Ceará.

\section{METODOLOGIA}

A pesquisa foi realizada no Catálogo de Teses e Dissertações da Capes ${ }^{1}$ em razão de ser um repositório de teses e dissertações dos programas de doutorado e mestrado reconhecidos pela agência e onde é possível realizar a busca por autor, título e/ou palavra-chave das produções acadêmicas, desde 1987.

$\mathrm{Na}$ realização desse inventário foram selecionados oito verbetes julgados relevantes para dar maior abrangência ao tema e contemplar a maior quantidade de trabalhos, quais sejam: políticas de avaliação educacional, avaliação, Ideb, avaliação educacional, política educacional, municipalização do ensino, avaliação externa e bons resultados. Em cada busca foi selecionada Educação como área do conhecimento, e o período de 2005 a 2017, como recorte temporal.

Foram encontradas 294 produções e, num primeiro momento, analisadas observando o título, com o objetivo de perceber alguma relação com a temática 'políticas de avaliação educacional', o que possibilitou encontrar um total de 47 trabalhos. Em seguida, com a apreciação dos resumos foi possível identificar treze trabalhos relacionados com avaliação educacional em municípios brasileiros, sendo três teses e dez dissertações, defendidas entre os anos de 2010 a 2016.

1https://catalogodeteses.capes.gov.br/ 
Nesses treze trabalhos, a abordagem das políticas de avaliação educacional pode ser observada a partir de quatro vertentes:

- pesquisas que focalizam a atuação de escolas frente às avaliações externas. Relatam iniciativas específicas de escolas que se destacam em seus indicadores.

- estudos que se debruçam sobre as implicações negativas das políticas de avaliação educacional para a gestão escolar, com reflexos na sala de aula, especificamente no trabalho do professor.

- pesquisas que tecem críticas a respeito dos instrumentos de avaliação de larga escala, refletindo sobre sua utilização como mecanismo de controle ou regulação.

- estudos que investigam iniciativas de políticas de avaliação de larga escala em municípios, no ensino fundamental, com implicações dessas ações no ensino, no currículo, na rotina escolar, contando com o depoimento de gestores educacionais e escolares.

A Tabela 1 apresenta o detalhamento dos trabalhos organizados por autor, ano de publicação, nível acadêmico e instituição de ensino superior.

Tabela 1: Dissertações e teses sobre políticas de avaliação educacional: consulta no Catálogo de Teses e Dissertações da Capes

\begin{tabular}{|c|c|c|c|c|c|}
\hline Ord. & Autor & Ano & Título & Nível & IES \\
\hline 1 & FILHO & 2010 & $\begin{array}{l}\text { Bons resultados no Ideb em } \\
\text { municípios cearenses: sucesso escolar } \\
\text { sem novas tecnologias? }\end{array}$ & Mestrado & $\begin{array}{l}\text { Universidade } \\
\text { Estadual do Ceará }\end{array}$ \\
\hline 2 & LIMA & 2011 & $\begin{array}{l}\text { A política educacional em municípios } \\
\text { com bons resultados no Ideb: } \\
\text { mapeamento de características }\end{array}$ & Mestrado & $\begin{array}{c}\text { Universidade } \\
\text { Federal da Grande } \\
\text { Dourados }\end{array}$ \\
\hline 3 & OVANDO & 2011 & $\begin{array}{c}\text { A avaliação na política educacional de } \\
\text { municípios Sul-Mato-Grossenses }\end{array}$ & Mestrado & $\begin{array}{c}\text { Universidade } \\
\text { Federal da Grande } \\
\text { Dourados }\end{array}$ \\
\hline 4 & SILVA & 2012 & $\begin{array}{l}\text { Um estudo sobre o índice de } \\
\text { desenvolvimento da educação básica } \\
\text { (Ideb):como as escolas públicas de } \\
\text { Juiz de Fora melhoraram o seu } \\
\text { desempenho }\end{array}$ & Mestrado & $\begin{array}{l}\text { Universidade } \\
\text { Federal de Juiz de } \\
\text { Fora }\end{array}$ \\
\hline 5 & ANJOS & 2013 & $\begin{array}{l}\text { A avaliação nas escolas públicas } \\
\text { municipais de Florianópolis: avaliar } \\
\text { para regular }\end{array}$ & Mestrado & $\begin{array}{c}\text { Universidade } \\
\text { Federal de Santa } \\
\text { Catarina }\end{array}$ \\
\hline 6 & ASSUMPÇÃO & 2013 & $\begin{array}{l}\text { A correlação das práticas avaliativas } \\
\text { no interior da escola com a política } \\
\text { de controle público por meio da } \\
\text { avaliação: um estudo em Duque de } \\
\text { Caxias/RJ }\end{array}$ & Mestrado & $\begin{array}{c}\text { Universidade } \\
\text { Federal do Estado } \\
\text { do Rio de Janeiro }\end{array}$ \\
\hline
\end{tabular}


DOI: $10.12957 /$ teias.2020.44105

\begin{tabular}{|c|c|c|c|c|c|}
\hline 7 & ROCHA & 2013 & $\begin{array}{c}\text { A inserção do Índice de } \\
\text { desenvolvimento da educação básica } \\
\text { em escolas de ensino fundamental de } \\
\text { Teresina - Piauí: um estímulo para a } \\
\text { melhoria da educação? }\end{array}$ & Mestrado & $\begin{array}{l}\text { Universidade de } \\
\text { Brasilia }\end{array}$ \\
\hline 8 & SOARES & 2013 & $\begin{array}{c}\text { Política de gestão para o sistema de } \\
\text { avaliação da educação do Rio Grande } \\
\text { do Sul nas escolas estaduais do } \\
\text { município de Gravataí }\end{array}$ & Mestrado & $\begin{array}{l}\text { Universidade } \\
\text { Federal de Juiz de } \\
\text { Fora }\end{array}$ \\
\hline 9 & ROSA & 2014 & $\begin{array}{c}\text { Avaliação externa como estratégia de } \\
\text { gestão dos processos educacionais: } \\
\text { uma análise de políticas municipais } \\
\text { no Rio Grande do Sul }\end{array}$ & Doutorado & $\begin{array}{l}\text { Universidade do } \\
\text { Vale do Rio dos } \\
\quad \text { Sinos }\end{array}$ \\
\hline 10 & ASSIS & 2014 & $\begin{array}{c}\text { O Ideb nas escolas da rede municipal } \\
\text { de ensino de Jataí/GO: qualidade, } \\
\text { avaliação e interferências }\end{array}$ & Doutorado & $\begin{array}{l}\text { Universidade } \\
\text { Federal de Goiás }\end{array}$ \\
\hline 11 & VIEIRA & 2014 & $\begin{array}{c}\text { Políticas de avaliação em larga escala } \\
\text { e suas implicações para o trabalho } \\
\text { docente em escolas públicas do } \\
\text { município de Viçosa/MG }\end{array}$ & Mestrado & $\begin{array}{l}\text { Universidade } \\
\text { Federal de Viçosa }\end{array}$ \\
\hline 12 & FARIAS & 2015 & $\begin{array}{l}\text { Avaliação externa e gestão da escola: } \\
\text { apropriações e usos dos dados do } \\
\text { Ideb na gestão de escolas públicas } \\
\text { municipais de Fortaleza }\end{array}$ & Mestrado & $\begin{array}{l}\text { Universidade } \\
\text { Estadual do Ceará }\end{array}$ \\
\hline 13 & PASINI & 2016 & $\begin{array}{c}\text { Políticas de avaliação em larga escala } \\
\text { e o contexto da prática em } \\
\text { municípios de pequeno porte do } \\
\text { estado do Paraná (2005/2013) }\end{array}$ & Doutorado & $\begin{array}{l}\text { Universidade do } \\
\text { Vale do Rio dos } \\
\text { Sinos }\end{array}$ \\
\hline
\end{tabular}

Fonte: Catálogo de Teses e Dissertações da Capes, 2019

Do total de trabalhos encontrados a partir dos oito verbetes selecionados, alguns achados merecem destaque:

- Das 294 produções inicialmente encontradas, 94\% concentram-se de 2010 a 2017. Isso pode estar associado à incidência de iniciativas de avaliação educacional em estados e municípios, bem como no fortalecimento da política de responsabilização no país, que começa a ocorrer a partir da criação do Ideb, em 2005.

- Dos trabalhos encontrados, os anos de 2013 e 2014 são os que detém maior produção, totalizando sete publicações.

- Os Estados do Ceará, Mato Grosso do Sul, Minas Gerais e Rio Grande do Sul se destacam em número de investigações $(61,5 \%)$, situação que pode ter relação com a forte política de avaliação e monitoramento em seus territórios, como Ceará e Minas Gerais, pioneiros na criação de sistema próprio de avaliação. 
- Há uma proliferação de termos associados às políticas de avaliação educacional, como:

$\checkmark$ avaliação em larga escala (ANJOS, 2013; PASINI, 2016; SOARES, 2013; VIEIRA, 2014);

$\checkmark$ avaliação da educação básica (ASSIS, 2014);

$\checkmark$ controle público por meio da avaliação (ASUMPÇÃO, 2013);

$\checkmark$ avaliação externa (FARIAS, 2015; LIMA, 2011; OVANDO, 2011; ROCHA, 2013; ROSA, 2014; SILVA, 2012) e

$\checkmark$ sistema nacional de avaliação da educação básica (FILHO, 2010).

Os pontos em comum dessas denominações é o entendimento dos autores de que a política de avaliação é pensada externa à escola, sua abrangência é de larga escala e censitária, e exerce controle por meio de um sistema.

\section{A POLÍTICA EDUCACIONAL E A EMERGÊNCIA DOS SISTEMAS DE AVALIAÇÃO NO BRASIL}

O Brasil, assim como sistemas educacionais no mundo todo, tem sido influenciado por organismos internacionais a exemplo da Organização para a Cooperação Econômica e Desenvolvimento (OCDE) e do Banco Mundial (AMARAL, 2010), no que se refere a implantação de sistemas de avaliação de políticas educacionais.

Um exemplo do envolvimento do Brasil com iniciativas da OCDE é a adesão ao Programa Internacional de Avaliação de Estudantes (Pisa) que tem o Instituto Nacional de Estudos e Pesquisas Educacionais Anísio Teixeira (Inep) como coordenador no país. O exame é uma avaliação comparada e amostral de alunos de 15 anos de idade em três áreas - leitura, matemática e ciências -, e vem sendo aplicado desde 2000, de três em três anos. Portanto, se caracteriza como um instrumento de controle, a partir de comparação internacional (AMARAL, 2010). Programas como esse " $[. .$.$] incorporam frequentemente novos aperfeiçoamentos metodológicos, e abrem-se a$ uma maior diversidade de dimensões, que parecem distingui-los de muitos dos testes comparativos em larga escala, de âmbito nacional" (AFONSO, 2014, p. 490).

No mesmo sentido, o Banco Mundial, criado na conjuntura do final da Segunda Guerra Mundial, em 1944, como uma agência de financiamento internacional sem fins lucrativos, teve como intuito original disponibilizar recursos financeiros para países europeus e Japão visando a reestruturação das economias no período pós-guerra. Atualmente, tem como pré-requisito para inserção na carteira de empréstimos, países vinculados ao Fundo Monetário Internacional (FMI). O Brasil tornou-se um país-membro em 1993, a partir da adesão ao Banco Internacional de Reconstrução e Desenvolvimento (BIRD), uma das instituições que compõem o Banco Mundial. Com o propósito de orientar as ações em torno do desenvolvimento dos países, o Banco Mundial “[...] estabeleceu quatro dimensões-chave para a boa governança: administração do setor público; quadro legal; participação e accountability; e informação e transparência” (BORGES, 2003, p. 126).

Nesse cenário de globalização, a educação pública brasileira, nas últimas décadas, vem recebendo maior atenção dos governantes no sentido de investir na melhoria da qualidade do ensino. Outros países como Portugal, Canadá e Estados Unidos vêm desenvolvendo formas de monitoramento e investigação no campo educacional desde a década de 1980 (HOLANDA, 2006). No Brasil esse fenômeno é relativamente novo, tendo se concretizado, de forma tímida, em âmbito nacional a partir dos anos 1990, e se fortalecido depois dos anos 2000. Na visão de Brooke (2008, 
p. 94) "[...] o Brasil é um caso especialmente interessante, existindo avaliações nacionais em todos os níveis educacionais, incluindo o ensino superior".

No Brasil, segundo Bonamino e Franco (1999, p. 102), “[...] desde 1988 vêm sendo tomadas iniciativas voltadas à implantação e desenvolvimento do Sistema Nacional de Avaliação da Escola Básica (Saeb)". Ao analisarem o processo de institucionalização do Saeb, os autores, constataram que se deu em ciclos.

Deste modo, ainda na década de 1980 o país vivenciou ensaios promovidos pelo governo visando verificar $\mathrm{o}$

[...] desempenho do sistema educacional a nível do $1^{\circ}$ grau realizadas de diferentes formas, na tentativa de associar rendimento escolar a alguns fatores, uns mais abrangentes, como por exemplo, regiões do país em que as escolas se situam, outros, incluindo, além disso, período de funcionamento da escola (diurno/noturno), ou condições das escolas, das famílias dos professores, merenda escolar, custos etc. (GATTI, 1994, p. 67).

Uma das iniciativas pioneiras de avaliação em larga escala contemplando a educação básica foi o Programa de Expansão e Melhoria da Educação no Meio Rural (Edurural)², em 1981, que teve abrangência regional, realizada com o objetivo "[...] melhorar as condições do ensino na zona rural dos estados do Nordeste brasileiro" (GATTI, 1994, p. 68). Ele visava avaliar o impacto das ações desenvolvidas e representou um avanço do conhecimento sobre a situação do ensino público em uma dada realidade e de fatores associados ao desempenho dos alunos.

Alinhando as instruções do Banco Mundial às aspirações do MEC, foi se construindo um sistema de avaliação da educação básica abrangente e que fornecesse dados de rendimento escolar sistematizados, o que culminou na implantação do Sistema Nacional de Avaliação do Ensino Público de $1^{\circ}$ Grau (SAEP), com aplicação piloto ainda em 1988,

[...] nos estados do Paraná e Rio Grande do Norte, com o intuito de testar a pertinência e adequação de instrumentos e procedimentos. No entanto, dificuldades financeiras impediram o prosseguimento do projeto, que só pôde deslanchar em 1990, quando a Secretaria Nacional de Educação Básica alocou recursos necessários à viabilização do primeiro ciclo do Sistema Nacional de Avaliação do Ensino Básico (BONAMINO, FRANCO, 1999, p. 110).

Após esses ensaios, o Saeb se concretiza como a primeira iniciativa de âmbito nacional a se preocupar em obter dados sobre o desempenho escolar dos estudantes. Ele tem como objetivo realizar o monitoramento da educação básica nacional e tem sido aplicado pelo Inep a cada dois anos, junto a alunos de ensino fundamental e médio de todo o país desde 1990, inicialmente de forma amostral. Em 1995, a metodologia foi aprimorada com o uso da Teoria de Resposta ao Item (TRI) para possibilitar a comparação dos dados de desempenho no decorrer dos anos, e, a partir de então, começou a ser aplicado questionários contextuais. Desse modo, o sistema disponibiliza

\footnotetext{
2 Programa desenvolvido no Nordeste, nos Estados do Ceará, Pernambuco e Piauí, com duração de cinco anos (19811985) fruto da parceria entre MEC e BIRD, contemplou escolas rurais de 60 municípios. O estudo longitudinal de natureza quantitativa e qualitativa incluiu testes de rendimento escolar que permitiram o acompanhamento de 603 escolas rurais nas turmas de $2^{\mathrm{a}}$ e $4^{\mathrm{a}}$ séries do primeiro grau em Língua Portuguesa e Matemática (GATTI, 1994).
} 
informações aos governantes para o monitoramento, planejamento e/ou redefinição de políticas educacionais baseadas no diagnóstico da realidade.

Uma década depois o Saeb passa por modificações, com a publicação da Portaria Ministerial n. 931, de 21 de março de 2005, que cria duas avaliações: Avaliação Nacional da Educação Básica (Aneb) e Avaliação Nacional do Rendimento Escolar (Anresc), conhecida como Prova Brasil. Esta última configura-se como uma avaliação de larga escala universal, com realização de provas para estudantes matriculados na $4^{a}$ série $/ 5^{\circ}$ ano e $8^{a}$ série $/ 9^{\circ}$ ano do ensino fundamental das escolas públicas. O novo modelo permite a emissão de relatórios de resultados por estado, município, rede escolar e escola. Em 2013 foi integrada ao Saeb a Avaliação Nacional da Alfabetização (ANA) com a finalidade de verificar os níveis de alfabetização e letramento em Língua Portuguesa (leitura e escrita) e Matemática dos alunos matriculados no $3^{\circ}$ ano do ensino fundamental.

Nos últimos anos o Saeb passou por algumas inovações. Em 2017, incluiu os resultados das escolas públicas e privadas de ensino médio, e, consequentemente, estas passaram a possuir Ideb. A mudança mais recente ocorreu em 2019, extinguindo as siglas ANA, Aneb e Anresc, transformando-as em uma única denominação, Saeb.

Em 2007 foi criado o Índice de Desenvolvimento da Educação Básica (Ideb), um indicador que toma como elementos para a sua composição dados de aprovação escolar e de desempenho no Saeb. O cálculo para verificar as médias de desempenho para escolas e municípios é baseado nos resultados da Prova Brasil e para os estados e o país é realizado com base no Saeb ${ }^{3}$. Segundo o Inep o "[...] Ideb é um indicador educacional que relaciona, de forma positiva, informações de rendimento escolar (aprovação) e desempenho (proficiências) em exames padronizados, como a Prova Brasil e o Saeb". A relação entre fluxo e aprendizagem do Ideb vai traduzir em notas de 0 a 10 a trajetória dos sistemas de ensino, em âmbito nacional, nos estados, municípios e unidades de ensino. Na visão de Garcia et al. (2016, p. 96):

Trata-se de um indicador que tem como premissa a ideia de que um sistema educacional onde os estudantes fracassam sistematicamente e onde uma grande parte abandona a escola antes de completar a Educação Básica não é um sistema desejável, mesmo considerando que uma parcela dos jovens finalize a Educação Básica, atingindo altos desempenhos nos exames padronizados. Por outro lado, também não é desejável para um sistema que todos os alunos finalizem o Ensino Fundamental com pouco aprendizado, ainda que no período correto.

Quando de sua criação foram projetadas metas bianuais até 2021, baseadas nos dados divulgados referentes à linha de base de 2005 " [...] para que os estudantes das escolas brasileiras atinjam os padrões de desempenho apresentados pelos sistemas escolares dos países desenvolvidos, referenciando-se nos resultados do Programa Internacional de Avaliação da Aprendizagem (Pisa)" (GATTI et al., 2011, p. 40). Portanto, cada sistema deve progredir a partir de linha de base, e, consequentemente, exigindo maior empenho daqueles que iniciam em pior situação, estratégia que tem como objetivo a redução da desigualdade educacional.

O estabelecimento dessas metas é resposta às diretrizes do Banco Mundial, pois ele orienta "[...] que os sistemas educacionais estabeleçam uma especificação clara de objetivos e um maior monitoramento dos resultados e insumos" (BONAMINO; FRANCO, 1999, p. 119). A influência

\footnotetext{
${ }^{3}$ Nesse caso, são considerados os resultados da Anresc e Aneb.
} 
dessa agência como indutora da política de avaliação dos países não-membros é marcante e orienta os protocolos para recebimento de futuros empréstimos.

As metas estabelecidas devem ser alcançadas não apenas pelo país, mas também por estados e Distrito Federal, municípios e escolas. O propósito é responsabilizar cada ente federado em seu nível de abrangência e as redes de ensino, para que avancem em direção as metas projetadas pelo Ministério da Educação.

\section{CATEGORIAS QUE PERMEIAM A POLÍTICA DE AVALIAÇÃO EDUCACIONAL}

Bonamino e Sousa (2012, p. 373) consideram a trajetória das políticas avaliativas analisando seus objetivos e desenhos. Isso permitiu diferenciar as avaliações em larga escala em três gerações, sendo que:

A primeira geração consiste na avaliação diagnóstica da qualidade da educação, sem atribuição de consequências diretas para as escolas e para o currículo escolar. As outras duas gerações articulam os resultados das avaliações a políticas de responsabilização, com atribuição de consequências simbólicas ou materiais para os agentes escolares.

As autoras esclarecem que, ao mesmo tempo em que as gerações se sucedem, a anterior não se extingue, coexistindo no âmbito das redes de ensino e que em face desta ponderação é possível considerar tal classificação, essencialmente, como um recurso analítico. No Brasil, é perceptível os avanços na política de avaliação de larga escala desde a criação do Saeb, que possibilitou estabelecer métricas para acompanhar a evolução da qualidade da educação, com divulgação pública dos resultados obtidos de forma agregada, permitindo a identificação de tendências e comportamentos das redes escolares.

A partir das modificações implementadas no Saeb em 2005, inicia-se a ampliação do sistema de coleta de dados, permitindo a estratificação das informações à nível de escola, o que fornece diagnósticos mais objetivos e detalhados e, acima de tudo, permite aos sujeitos envolvidos se perceberem nos resultados.

Conforme Bonamino e Sousa (2012), a partir da segunda e terceira gerações as avaliações passaram a compor as políticas de responsabilização, portanto agregam outra finalidade, a de atribuir consequências para os agentes escolares, considerando os resultados dos alunos. $\mathrm{Na}$ segunda geração, as consequências são apenas de natureza simbólica, ou seja, responsabilização branda, pois além da divulgação pública dos resultados, eles são entregues às escolas e transmitidos aos pais e a sociedade que podem pressionar para que a gestão escolar e professores se esforcem no aprendizado dos alunos. Nesse momento, não há consequências materiais. $\mathrm{Na}$ terceira geração, as consequências se agravam, pois são adicionadas recompensas em decorrência do desempenho dos alunos, caracterizando um cenário de responsabilização forte que envolve atribuição de premiação e bônus para aqueles que atingirem as metas estabelecias (BONAMINO; SOUSA, 2012, p. 375). Nesse sentido a pesquisa de Sousa e Oliveira (2010) também evidenciou que avaliações estaduais vêm associando o desempenho dos alunos à carreira docente, criando mecanismos que incluem gratificações, bônus e até mesmo certificação para professores.

Um entrave decorrente da evolução das avaliações diz respeito ao alinhamento das avaliações internas inerentes à escola, às avaliações externas, gerando preocupação de diretores e 
professores com a preparação para os testes, e o consequente estreitamento do currículo escolar (VIDAL, VIEIRA, 2011). A relação entre a avaliação de larga escala e o currículo escolar pode ser encarada como as duas faces de uma mesma moeda. Por um lado, a redução do currículo escolar às disciplinas avaliadas e às matrizes de referência das avaliações externas, considerando-se que estas "[...] valorizam apenas determinados conteúdos curriculares e, consequentemente, certas dimensões e processos de aprendizagem" (AFONSO, 2014, p. 490). E de outro, o avanço da possibilidade de olhar para o currículo escolar e poder perceber as "[...] habilidades fundamentais de leitura e matemática que ainda não têm sido garantidas a todos os alunos" (AFONSO, 2014, p. 373), observado nas avaliações de segunda e terceira geração.

Afonso (2014, p. 488) ainda destaca que outro entrave das políticas de avaliação é a excessiva centralidade quanto aos esforços e investimentos para a avaliação dos alunos, em detrimento dos demais setores relacionados com a aprendizagem, e que tem a mesma importância para o funcionamento e desenvolvimento da educação. Para ele:

Numa época em que, por razões diversas, a avaliação das aprendizagens, a avaliação institucional das escolas, a avaliação do desempenho docente e a própria avaliação de políticas coexistem nos sistemas educativos, torna-se indispensável, [...], chamar a atenção para a necessidade de analisar criticamente a excessiva centralidade da avaliação dos alunos, à qual todas as outras avaliações parecem subordinar-se ou referenciar-se.

O termo avaliocracia, utilizado por Correia (2005) e Afonso (2008), designa esse momento histórico, iniciado nas últimas décadas, em que o enfoque principal é a avaliação e que causou um processo de obsessão avaliativa que:

[...] tornou-se dominante, invadindo não apenas os contextos tradicionais de interação pedagógica (como as salas de aula), mas também as organizações educativas (e não educativas), os sistemas de ensino e a própria administração pública. Esta obsessão avaliativa começou por contaminar os governos (nacionais, subnacionais e municipais), os quais, de forma crescente, passaram a agir em congruência com a ideologia avaliativa hegemónica (AFONSO, 2014, p. 490).

A aplicação periódica de provas simuladas nas turmas que serão avaliadas, utilizando-se de instrumentos que se assemelham aos adotados em avaliações externas tem se popularizado nas escolas públicas e nas redes de ensino. Um exemplo disso é a situação, citada por Bonamino e Sousa (2012, p. 383), "[...] conhecida como ensinar para o teste, que ocorre quando os professores concentram seus esforços preferencialmente nos tópicos que são avaliados e desconsideram aspectos importantes do currículo, inclusive de caráter não cognitivo". Na visão de Afonso (2014, p. 489) o modelo engessado das avaliações "[...] tem recuperado as velhas fórmulas dos exames nacionais, ainda que atualizadas em aspetos técnico-metodológicos e concretizadas através de instrumentos estandardizados, supostamente mais válidos e fidedignos do que em épocas passadas".

A atribuição de prêmios aos melhores constitui-se um incentivo para que permaneçam avançando, ao tempo em que a falta de apoio financeiro, para aqueles que não obtiveram bons resultados, representa uma punição. Dessa forma, Afonso (2014, p. 493) enxerga esse mecanismo como algo que " $[. .$.$] tem vindo a ampliar-se a introdução de bônus monetários, que são atribuídos$ de forma diferenciada aos professores ou às escolas, como consequência das performances discentes 
alcançadas". Na visão do autor (AFONSO, 2014, p. 495), muito melhor, urgente e justo seria “[...] aumentar significativamente os salários dos professores, adotar modelos de avaliação profissional amplamente discutidos e democraticamente consensualizados, e dignificar de vez o seu estatuto socioprofissional".

Uma estratégia adotada na busca pela melhoria dos resultados nas avaliações externas é a divulgação desses dados pela mídia, realizando comparação entre escolas e municípios, baseada em rankings, quando deveriam ser confrontados os resultados anteriores e o atual para que fosse observado o seu progresso individual. Assim, seria verificada sua evolução, possibilitando um melhor planejamento de ações para o alcance de metas particulares, de acordo com a realidade e não a valorização dos melhores, generalizando os contextos. E como consequência disso:

A estratégia da mídia de divulgação, por meio de rankings, embora não oficial, juntamente com a distribuição nas escolas da matriz de conteúdos e habilidades utilizada na elaboração dos testes de língua portuguesa e matemática, introduz perspectivas concretas de interferência mais direta no que as escolas fazem e em como o fazem (BONAMINO, SOUSA, 2012, p. 375).

As avaliações educacionais são aliadas das políticas de responsabilização, pois fortalecem os interesses do governo para que haja a "[...] descentração/desresponsabilização em relação a problemas diretamente imputáveis aos governos, mas que são transferidos para a responsabilidade dos atores, dos gestores escolares e das organizações educativas" (AFONSO, 2014, p. 492).

Após refletir sobre alguns avanços e entraves no decorrer da consolidação das políticas de avaliação educacional no Brasil, observa-se que estas estão diretamente relacionadas com as políticas de accountability que vêm, gradativamente, sendo implantadas nos sistemas de ensino, tendo a avaliação em larga escala como carro chefe. Essas práticas avaliativas, no decorrer do seu percurso histórico, têm tomado outros rumos trazendo implicações fracas e fortes, com sanções ou recompensas, para as escolas e professores, pelos resultados dos alunos. Estratégias utilizadas para obtenção de maior empenho dos professores e gestores para o alcance de melhores resultados acabam por interferir no comportamento desses atores.

\section{PESQUISAS INVENTARIADAS}

As treze pesquisas foram inventariadas a partir dos seguintes identificadores: objetivo geral, ente federado investigado, instrumentos de coleta dos dados, critérios de escolha das escolas, sujeitos participantes e resultados encontrados.

$\mathrm{Na}$ análise dos objetivos gerais de cada tese e dissertação selecionada o intuito foi conhecer o foco dos estudos. Agrupando-os por proximidade de interesses, identificou-se sete categorias: políticas de avaliação educacional; ações das escolas; interferência do Ideb; contribuição das Tecnologias de Informação e Comunicação (TIC); avaliação do impacto das políticas de avaliação educacional; atuação da Coordenadoria Regional; avaliação da importância das avaliações.

No que se refere aos loci das pesquisas foram identificados 32 municípios $^{4}$, em 9 estados, como mostra a Figura 1.

${ }^{4}$ Faz-se necessário esclarecer que dois trabalhos, dos treze analisados, possuem a mesma amostra, uma vez que ambos derivam de uma mesma pesquisa mais robusta. 
Figura 1: Quantidade de produções por estado e municípios envolvidos

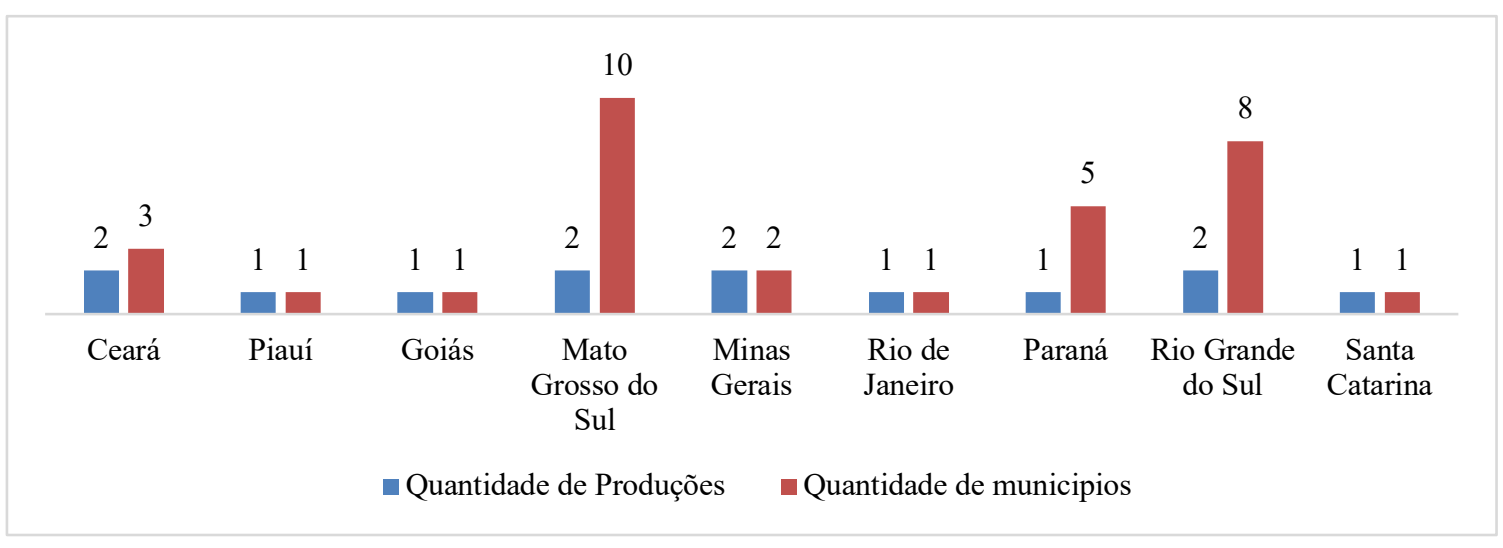

Fonte: Catálogo de Teses e Dissertações da Capes, 2019

Considerando as cinco regiões brasileiras, a predominância dos trabalhos se concentra na região Sul (4), envolvendo 14 municípios, seguida das regiões Centro-Oeste (3) e Nordeste (3), investigando 11 e 4 municípios, respectivamente. A região Sudeste responde por 3 trabalhos e 3 municípios e a região Norte não tem produção identificada.

Quanto aos instrumentos de coleta dos dados utilizados, a maioria aplicou somente roteiro de entrevista (9), e em alguns casos está acompanhado do questionário (5). Diferencia-se uma pesquisa que não recorreu a nenhum instrumento, por se deter apenas à análise documental. A utilização desses justifica-se pelos objetivos das pesquisas que, em sua maioria, buscam conhecer as políticas municipais de avaliação educacional e compreender a interferência do Ideb na gestão escolar e na prática pedagógica, por meio do relato dos sujeitos envolvidos no processo.

Em relação ao critério de escolha das escolas, na maioria das vezes, a definição obedeceu a mais de um critério, sendo distribuída em seis classificações. Dentre estas, a nota do Ideb foi recorrente em três situações: apenas nota do Ideb (5); nota do Ideb vinculada à localização (3); e nota do Ideb relacionada ao nível socioeconômico (1). Duas pesquisas não contemplaram visita à escola, uma por se deter à análise documental e a outra, às entrevistas aos gestores das redes municipais.

A nota do Ideb é fator diretamente associado à metodologia das pesquisas inventariadas, por se tratar de um indicador que tem se firmado como relevante e parâmetro de medida para avaliar a qualidade do ensino para todas as escolas da rede municipal do país. Portanto, é um critério muito utilizado para respaldar a cientificidade das investigações.

Os sujeitos participantes das pesquisas distinguem-se em dez tipos, pertencentes ao âmbito educacional e escolar, no entanto, observa-se a figura do diretor presente na maioria dos trabalhos (9), e em segundo lugar estão os coordenadores (7), e logo após os professores (6) e técnicos (6). O relato dos diretores escolares é priorizado nas pesquisas, dada a importância do seu papel na implementação das políticas públicas municipais. Esses estão na linha de frente da gestão de todo o processo de ensino-aprendizagem e podem ser bem-sucedidos ou não, dependendo do andamento das variáveis envolvidas.

No que concerne aos resultados obtidos pelas teses e dissertações, a maioria aponta uma variedade de evidências e, por isso, buscou-se dar destaque às mais relevantes em cada pesquisa. 
Comparando os achados apontados individualmente, elegeu-se treze categorias relacionadas a gestão educacional e/ou escolar, como mostra a Tabela 2.

Tabela 2: Categorias identificadas e autores associados

\begin{tabular}{|c|c|c|c|}
\hline Ord. & Categorias & Prod. & Autor/ano \\
\hline 1 & $\begin{array}{c}\text { Presença de avaliações nas escolas baseadas } \\
\text { nas Matrizes de Referência da Prova Brasil }\end{array}$ & 5 & $\begin{array}{c}\text { ANJOS (2013), ASSIS (2014), } \\
\text { ASSUMPÇÂO (2013), SILVA (2012), } \\
\text { VIEIRA (2014) }\end{array}$ \\
\hline 2 & $\begin{array}{c}\text { Rede com iniciativas próprias de avaliação } \\
\text { e monitoramento }\end{array}$ & 4 & $\begin{array}{l}\text { ANJOS (2013), ASSUMPÇÃO (2013), } \\
\text { OVANDO (2011), ROSA (2014) }\end{array}$ \\
\hline 3 & $\begin{array}{l}\text { Avaliações externas são conteúdo da } \\
\text { formação continuada dos professores }\end{array}$ & 3 & $\begin{array}{l}\text { ANJOS (2013), ROCHA (2013), ROSA } \\
\text { (2014) }\end{array}$ \\
\hline 4 & $\begin{array}{c}\text { Resistência às avaliações em larga escala } \\
\text { por parte dos professores }\end{array}$ & 2 & ANJOS (2013), PASINI (2016) \\
\hline 5 & $\begin{array}{l}\text { Ideb como elemento orientador das } \\
\text { políticas públicas educacionais das redes }\end{array}$ & 2 & OVANDO (2011), ROCHA (2013) \\
\hline 6 & $\begin{array}{l}\text { Política municipal de responsabilização e } \\
\text { meritocracia }\end{array}$ & 2 & ASSUMPÇÃO (2013), PASINI (2016). \\
\hline 7 & $\begin{array}{l}\text { Ausência de orientação às escolas para } \\
\text { utilização dos dados das avaliações externas }\end{array}$ & 2 & FARIAS (2015), SOARES (2013) \\
\hline 8 & $\begin{array}{c}\text { Escola com projeto pedagógico baseado } \\
\text { nas avaliações internas e externas }\end{array}$ & 1 & FARIAS (2015) \\
\hline 9 & $\begin{array}{c}\text { Presença ou ausência de computadores não } \\
\text { explica os resultados }\end{array}$ & 1 & FILHO (2010) \\
\hline 10 & Baixo nível de coordenação das redes & 1 & LIMA (2011) \\
\hline 11 & $\begin{array}{l}\text { Políticas educacionais com características } \\
\text { subsidiárias }\end{array}$ & 1 & LIMA (2011) \\
\hline 12 & Estreitamento curricular & 1 & VIEIRA (2014) \\
\hline 13 & $\begin{array}{l}\text { "Treinamento" para as avaliações e } \\
\text { reforços para as disciplinas avaliadas }\end{array}$ & 1 & VIEIRA (2014) \\
\hline
\end{tabular}

Fonte: Catálogo de Teses e Dissertações da Capes, 2019

$\mathrm{Na}$ análise dos resultados encontrados por cada autor, a maioria deles chegou a mais de uma constatação. Destaca-se alguns trabalhos como do Anjos (2013) que constatou a presença de iniciativas próprias de avaliação e monitoramento na rede investigada, e verificou a presença de avaliações nas escolas, baseadas nas matrizes de referência da Prova Brasil e Provinha Brasil. Outra constatação diz respeito ao tema das avaliações externas se fazer presente como conteúdo da formação continuada dos professores e a resistência deles a este tipo de avaliação. De igual modo, 
Pasini (2016) constatou que há resistência dos profissionais para que as especificidades das avaliações externas não sejam determinantes da prática pedagógica escolar.

Assumpção (2013) reflete sobre o poder de regulação do Estado-avaliador (AFONSO, 2003), nesse caso, em nível municipal, ao identificar uma política de avaliação bem definida e consolidada (Prova Caxias). Acrescenta que os docentes desenvolvem estratégias pedagógicas que visam controlar o baixo desempenho dos alunos, se utilizando das matrizes de referência dos exames e que o compromisso e a dedicação deles estão associados aos resultados dos alunos, culminando no fortalecimento das políticas de responsabilização (ASSUMPÇÃO, 2013).

Assis (2014) identifica alguns impactos na gestão municipal e escolar da rede investigada com o surgimento do Ideb. Visando a melhoria de seus resultados, medidas como a utilização de outras formas de avaliação no contexto escolar tem ajudado no alcance de suas metas. Afirma ainda, que a gestão da rede municipal procura alcançar as metas previstas pelo Ideb e, para isso, fomentou estratégias pedagógicas com vistas a melhorar o desempenho dos estudantes.

Rocha (2013, p. 8) acrescenta que o Ideb, como instrumento da política de avaliação educacional, tem refletido positivamente nas unidades educacionais, pois graças a ele, a gestão municipal concentrou suas ações nas avaliações de desempenho dos alunos de toda a rede, na formação do professor e no envolvimento da comunidade escolar. Segundo ele, "[...] o estudo também levou à compreensão de que as políticas públicas educacionais, quando são implantadas e apropriadas pelos sujeitos, podem produzir efeitos positivos nas instituições escolares".

Em contrapartida, Ovando (2011, p. 6) conclui que a "[...] incorporação / apropriação da avaliação ocorrem de forma ativa, porém reprodutora, restrita, nem sempre sistemática e regular, visando melhoria da qualidade do ensino e defesa da autonomia municipal".

No processo de apropriação dos resultados das avaliações externas o papel do sistema de ensino é primordial, no sentido de orientar as escolas para uso dos dados, visando a minimização das deficiências apontadas. Quando não há essa parceria, a própria unidade de ensino tem que se mobilizar para, por si só, interpretar os dados e pensar estratégias de trabalho para melhorar seu desempenho. A esse respeito, Farias (2015) observou, na rede analisada, a inexistência de políticas que dessem suporte às escolas na análise dos dados das avaliações, o que só veio acontecer no final de 2010, com o Programa Alfabetização na Idade Certa, mas que ficou restrito ao primeiro segmento do ensino fundamental.

Do mesmo modo, Lima (2011, p. 8) constatou o “[...] baixo nível de coordenação das redes, as políticas com características democráticas ficaram com nível mediado e a subsidiariedade ficou um pouco mais evidente". E Soares (2013) observou que a Coordenação Regional enfrentou dificuldades na divulgação dos resultados dos indicadores educacionais e as escolas não conseguiram se apropriar dos dados.

Rosa (2014, p. 9) também identificou municípios que organizaram uma prática avaliativa com foco na proficiência dos alunos (provas) e entre esses há aqueles que institucionalizaram suas avaliações, destacando que "[...] as ações desses municípios no campo da gestão educacional tiveram relevo, tendo como ponto de partida os indicadores de qualidade educacional voltados para o investimento formativo, desempenho, sucesso e fracasso escolar".

Observa-se ainda que dentre os treze trabalhos inventariados, apenas três dissertações consideraram a evolução no Ideb como critério de escolha de seus municípios (FILHO, 2010; LIMA, 2011; OVANDO, 2011). Nesse sentido, a principal lacuna é a falta de estudos mais recentes 
sobre a temática, tendo em vista que foram desenvolvidos com base nos resultados dos dois primeiros anos da avaliação (2005 e 2007).

\section{CONSIDERAÇÕES FINAIS}

As pesquisas apontam pistas interessantes e uma delas é o envolvimento dos atores escolares na implementação das estratégias concebidas pelos órgãos municipal, estadual e federal visando à melhoria dos indicadores educacionais atrelados às políticas de avaliação. Eles agem como sujeitos que interpretam e reinterpretam as iniciativas que chegam às escolas, executando de forma singular, conforme seu entendimento, e dentro das possibilidades proporcionadas por sua realidade (BALL, MAGUIRRE, BRAUN, 2016, p. 13), no entanto, a centralidade que as avaliações de larga escala ocupam no cotidiano dos gestores, uma vez que se propaga em efeito cascata do poder central (Governo Federal) para as pontas (escolas), faz com que esses gestores tenham pouca margem de manobra no processo de implementação das políticas.

Exceto as pesquisas de Anjos (2013) e Pasini (2016) que identificaram algum tipo de resistência, por parte dos professores, às avaliações de larga escala, os demais trabalhos apontam para o fato de que os governos e as escolas passaram a agir atendendo a ideologia hegemônica da avaliação (AFONSO, 2014).

Os principais conceitos, referentes a políticas de avaliação, encontrados nos referenciais teóricos dos trabalhos analisados foram:

- Regulação (FREITAS, 2011, p. 3) “[...] se configura de maneira nítida a partir das propostas educacionais de controle do aparato escolar por meio de meritocracia e "responsabilização", controle dos métodos a partir de apostilamento de redes inteiras";

- Qualidade (SILVA, 2009, p. 291) "[...] dispõe de parâmetros de utilidade, praticidade e comparabilidade, envolvendo medidas e níveis mensuráveis, padrões, rankings, testes comparativos, hierarquização e estandardização próprias do âmbito mercantil";

- Accountability (BROOKE, 2006, p. 21), "[...] significa uma cobrança por bons resultados e a demanda de que cada um dos atores envolvidos assuma a sua responsabilidade na produção desses resultados";

- Estado-avaliador (AFONSO, 2003, p. 44) momento em que ao Estado é conferido um "[...] relativo aumento do poder de regulação e uma lógica mais voltada para o mercado ou para a autorregulação institucional".

A partir dos conceitos, foram identificadas as seguintes categorias: política de responsabilização ou accountability, uso dos resultados, redução do currículo, sistema de premiação ou bonificação e testes preparatórios. Estas trazem discussões pertinentes para uma melhor compreensão de como as políticas de avaliação educacional são pensadas e representadas em contextos materiais no âmbito de um sistema de ensino, apontando para a necessidade de discussão sobre a homogeneização de medidas que terminam por acontecer.

Este levantamento aponta caminhos e traz luz a discussões em torno das políticas de avaliação educacional no Brasil. 

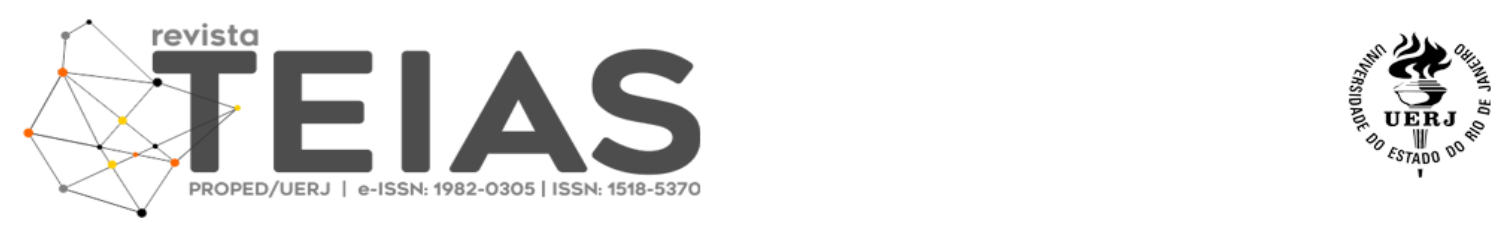

DOI: $10.12957 /$ teias.2020.44105

\section{REFERÊNCIAS}

AFONSO, Almerindo Janela. Estado, globalização e políticas educacionais: elementos para uma agenda de investigação. Revista Brasileira de Educação. Rio de Janeiro, n. 22, p. 35-46, jan./abr. 2003. AFONSO, Almerindo Janela. Para uma crítica da avaliocracia. Revista de Opinião Socialista, Lisboa, n. 2, p. 14-16, 2008.

AFONSO, Almerindo Janela. Questões, objetos e perspectivas em avaliação. Avaliação. Campinas; Sorocaba, São Paulo, v. 19, n. 2, p. 487-507, jul. 2014.

AMARAL, Marcelo Parreira do. Política pública educacional e sua dimensão internacional: abordagens teóricas. Educação e Pesquisa, São Paulo, v. 36, n. especial, p. 39-54, 2010.

ANJOS, Rosilene Amorim dos. A avaliação nas escolas públicas municipais de Florianópolis: avaliar para regular. 225f. Dissertação, Mestrado em Educação, Universidade Federal de Santa Catarina, Florianópolis, 2013.

ASSIS, Renata Machado de. O Ideb nas escolas da rede municipal de ensino de Jatai - GO: qualidade, avaliação e interferências. 302f. Tese, Doutorado em Educação, Universidade Federal de Goiás, Goiás, 2014.

ASSUMPÇÃO, Ester De Azevedo Correa. A correlaşão das práticas avaliativas no interior da escola com a política de controle público por meio da avaliação: um estudo em Duque de Caxias/RJ. 108f. Dissertação, Mestrado em Educação. Universidade Federal do Estado do Rio de Janeiro, Rio de Janeiro, 2013.

BALL, Stephen J.; MAGUIRRE, Meg; BRAUN, Annette. Como as escolas fazem as políticas: atuação em escolas secundárias. Ponta Grossa: Ed. UEPG, 2016.

BONAMINO, Alicia; FRANCO, Creso. Avaliação e política educacional: o processo de institucionalização do Saeb. Cadernos de Pesquisa, São Paulo, n. 108, p. 101-132, nov. 1999.

BONAMINO, Alicia; SOUSA, Sandra Zákia. Três gerações de avaliação da educação básica no Brasil: interfaces com o currículo da/na escola. Educação e Pesquisa, São Paulo, v. 38, n. 2, p. 373388, abr./jun. 2012.

BORGES, André. Governança e política educacional: a agenda recente do Banco Mundial. Revista Brasileira de Ciências Sociais. São Paulo, v. 18, n. 52, p. 125-138, 2003.

BROOKE, Nigel. O futuro das políticas de responsabilização educacional no Brasil. Cadernos de Pesquisa, São Paulo, v. 36, n. 128, p. 377-401, maio/ago. 2006.

BROOKE, Nigel. Responsabilização educacional no Brasil. Revista Iberoamericana de Evaluación Educativa. v. 1, n. 1. p. 93-108, 2008.

CORREIA, José Alberto Azevedo Vasconcelos. Contributos para a construção de "narrativas educativas" de esquerda. Perspectiva, Florianópolis, v. 23, n. 2, p. 407-426, 2005.

FARIAS, Maria Adalgiza de. Avaliação externa e gestão da escola: apropriações e usos dos dados do IDEB na gestão de escolas públicas municipais de Fortaleza. 227f. Dissertação, Mestrado em Educação. Universidade Estadual do Ceará, 2015.

FILHO, José Veríssimo do Nascimento. Bons resultados no Ideb em municípios cearenses: sucesso escolar sem novas tecnologias? 200f. Dissertação, Mestrado em Educação. Universidade Estadual do Ceará, 2010. 
FREITAS, Luiz Carlos. Responsabilização, meritocracia e privatização: conseguiremos escapar ao neotecnicismo? Seminário de Educação Brasileira, 3. Simpósio PNE - Diretrizes para Avaliação e Regulação da Educação Nacional. Campinas: CEDES, 2011.

GARCIA, Paulo Sérgio; PREARO, Leandro Campi; ROMERO, Maria do Carmo; SECCO, Anderson; BASSI, Marcos Sidnei. Desempenho escolar: uma análise do Ideb dos municípios da região do ABC. Revista Eletrônica de Educação, São Carlos - São Paulo, v. 10, n. 2, p. 95-114, 2016.

GATTT, Bernardete Angelina. Avaliação Educacional no Brasil: experiências, problemas, recomendações. Estudos em Avaliação Educacional. São Paulo, n. 10, p. 67-80, 1994.

GATTI, Bernardete Angelina; BARRETTO, Elba Siqueira de Sá; ANDRÉ, Marli Eliza Dalmazo Afonso de. Politicas docentes no Brasil: um estado da arte. Brasília: UNESCO, 2011.

HOLANDA, Marcos Costa (org.). Ceará: a prática de uma gestão por resultados. Fortaleza: IPECE, 2006.

LIMA, Simone Estigarribia de. A política educacional em municípios com bons resultados no IDEB mapeamento de características. 166f. Dissertação, Mestrado em Educação, Universidade Federal da Grande Dourados, Mato Grosso do Sul, 2011.

NÓBREGA-THERRIEN, Silvia Maria; THERRIEN, Jacques. O estado da questão: aportes teóricos-metodológicos e relatos de sua produção em trabalhos científicos. In: FARIAS, Isabel Maria Sabino de; NUNES, João Batista Carvalho; NÓBREGA-THERRIEN, Silvia Maria (orgs.). Pesquisa cientifica para iniciantes: caminhando no labirinto. Fortaleza, EdUECE, 2010.

OVANDO, Nataly Gomes. A avaliação na política educacional de municípios Sul-Mato-Grossenses. $127 \mathrm{f}$. Dissertação, Mestrado em Educação, Universidade Federal da Grande Dourados, Mato Grosso do Sul, 2011.

PASINI, Juliana Fatima Serraglio. Políticas de avaliação em larga escala e o contexto da prática em municípios de pequeno porte do estado do Paraná (2005/2013). 212 f. Tese, Doutorado em Educação, Universidade do Vale do Rio dos Sinos, Rio Grande do Sul, 2016.

ROCHA, Silvailde de Souza Martins. A inserção do indice de desenvolvimento da educação básica em escolas de ensino fundamental de Teresina - Piaui: um estímulo para a melhoria da educação? 167f. Dissertação, Mestrado em Educação, Universidade de Brasília, Brasília, 2013.

ROSA, Sonia Maria Oliveira da. Avaliação externa como estratégia de gestão dos processos educacionais: uma análise de políticas municipais no Rio Grande do Sul. 221f. Tese, Doutorado em Educação, Universidade do Vale do Rio dos Sinos, Rio Grande do Sul, 2014.

SILVA, Helaine Aparecida da. Um estudo sobre o indice de desenvolvimento da educação básica (Ideb): como as escolas públicas de Juiz de Fora melhoraram o seu desempenho. 126f. Dissertação, Mestrado em Educação, Universidade Federal de Juiz de Fora, Minas Gerais, 2012.

SILVA, Maria Abádia da. Qualidade social da educação pública: algumas aproximações. Cad. Cedes, Campinas - São Paulo, v. 29, n. 78, p. 216-226, maio/ago. 2009.

SOARES, Alexandre Rodrigues. Politica de gestão para o sistema de avaliaşão da educação do Rio Grande do Sul nas escolas estaduais do município de Gravataí. 85f. Dissertação, Mestrado Profissional em Gestão e Avaliação da Educação Pública, Universidade Federal de Juiz de Fora, Minas Gerais, 2013. 
SOUSA, Sandra Zákia; OLIVEIRA, Romualdo Portela de. Sistemas estaduais de avaliação: uso dos resultados, implicações e tendências. Cadernos de Pesquisa, São Paulo, v. 40, n. 141, p. 793-822, set./dez. 2010.

VIDAL, Eloisa Maia; VIEIRA, Sofia Lerche. Gestão educacional e resultados no Ideb: um estudo de caso em dez municípios cearenses. Estudos em avaliação educacional. São Paulo, v. 22, n. 50. p. 419434, 2011.

VIEIRA, Raquel Arrieiro. Políticas de avaliação em larga escala e suas implicações para o trabalho docente em escolas públicas do município de Viçosa - MG. 135f. Dissertação, Mestrado em Educação, Universidade Federal de Viçosa, 2014.

Submetido em julbo de 2019 Aprovado em janeiro de 2020

\section{Informações das autoras}

Ana Lídia Lopes do Carmo Monte

Programa de Pós-graduação em Educação da Universidade Estadual do Ceará E-mail: lidia lopesc@hotmail.com

ORCID: 0000-0002-6752-5763

Link Lattes: http://lattes.cnpq.br/8253803107321728

Eloisa Maia Vidal

Programa de Pós-graduação em Educação da Universidade Estadual do Ceará

E-mail: eloisamvidal@yahoo.com.br

ORCID: 0000-0003-0535-7394

Link Lattes: http://lattes.cnpq.br/4257594561432768 